OPEN ACCESS

Edited by:

Juan J. Canales,

University of Tasmania, Australia

Reviewed by:

Rune Elvik,

Institute of Transport Economics,

Norway

${ }^{*}$ Correspondence:

Sorin Hostiuc

soraer@gmail.com;

sorin.hostiuc@umfcd.ro

†These authors have contributed equally to this work.

Specialty section: This article was submitted to

Neuropharmacology,

a section of the journa

Frontiers in Pharmacology

Received: 26 February 2018

Accepted: 11 May 2018

Published: 29 May 2018

Citation:

Hostiuc S, Moldoveanu A, Negoci I and Drima E (2018) Corrigendum: The

Association of Unfavorable Traffic

Events and Cannabis Usage: $A$

Meta-Analysis.

Front. Pharmacol. 9:564.

doi: 10.3389/fphar.2018.00564

\section{Corrigendum: The Association of Unfavorable Traffic Events and Cannabis Usage: A Meta-Analysis}

\author{
Sorin Hostiuc ${ }^{1 * t}$, Alin Moldoveanu ${ }^{2}$, Ionuţ $\mathrm{Negoi}^{3 \dagger}$ and Eduard Drima ${ }^{4,5}$ \\ 'Department of Legal Medicine and Bioethics, Carol Davila University of Medicine and Pharmacy, Bucharest, Romania, \\ ${ }^{2}$ Faculty of Automatic Control and Computers, Polytechnic University of Bucharest, Bucharest, Romania, ${ }^{3}$ Department of \\ Surgery, Carol Davila University of Medicine and Pharmacy, Bucharest, Romania, ${ }^{4}$ Clinical-Medical Department, Faculty of \\ Medicine and Pharmacy, University Dunărea de Jos, Galați, Romania, ${ }^{5}$ Galati Psychiatry Hospital, Galați, Romania
}

Keywords: cannabis, driving under the influence of cannabis, death, injury, collision, inverse variance heterogeneity

\section{A corrigendum on}

The Association of Unfavorable Traffic Events and Cannabis Usage: A Meta-Analysis by Hostiuc, S., Moldoveanu, A., Negoi, I., and Drima, E. (2018). Front. Pharmacol. 9:99. doi: 10.3389/fphar.2018.00099

1. In the results section, in the subchapter "Driving under the influence of Cannabis-Blood Analysis," there was an error in the submitted manuscript. The error consisted in the presence of an additional reference in the studies included in the analysis, and the lack of two references from the studies included in the analysis. The overall results are very similar and do not change the scientific conclusions of the article in any way. The correct text for this subchapter, including all corrections (in bold), is:

"Ten studies included data that allowed us to reconstruct a proper methodological blood analysis of the samples taken from drivers (Longo et al., 2000; Movig et al., 2004; Laumon et al., 2005; Mura et al., 2006; Gmel et al., 2009; Gjerde et al., 2011; Kuypers et al., 2012; Hels et al., 2013; Li et al., 2013; Asbridge et al., 2014). By including them in the analysis, we found a modest increase in the OR to $1.97, \mathrm{CI}=(1.35-2.87)$, with a PI of 0.59-6.49 (Figure 5). The effect size difference between the values obtained for "DUIC-unadjusted" and "DUIC-blood analysis" was not statistically significant $\left(Z_{\text {diff }}=-0.19, p=0.84\right)$. The Rosenthal fail-safe $\mathrm{N}$ had a $Z$-score $3.18(p<0.001)$, suggesting that there should be added 171 missing studies to bring the $p$-value over alpha (1.96). The Duval and Tweedie's Trim and Fill method did not adjust the OR (no studies were trimmed). The effect size, as computed using the IVhet method, was 2.01 (1.23-3.29)."

2. Additionally, due to the above-mentioned error, a few other small changes were made, namely:

a. In the Abstract, Results, line 3, instead of " with an odds ratio (OR) of 2.27 and a confidence interval (CI) between 1.36 and 3.80" should read: "with an odds ratio (OR) of 1.97 and a confidence interval (CI) between 1.35 and 2.87" 


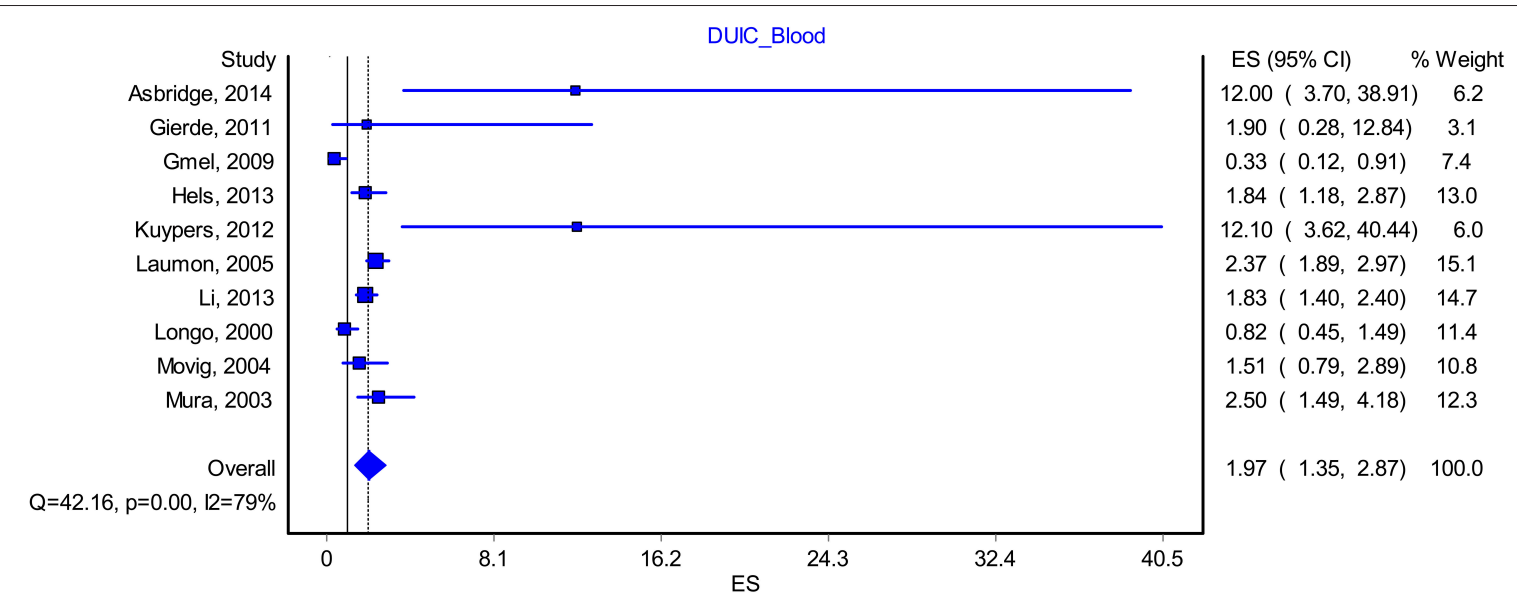

FIGURE 5 | Forrest plot. Studies that estimated DUIC through blood analysis (RE Model).

b. In the Results chapter, the subchapter "DUIC through self-reports", instead of "The effect size difference between DUIC-blood analyses and DUIC through self-reports was not statistically significant $\left(Z_{\text {diff }}=-0.58, p=0.56\right)$ " should read: "The effect size difference between DUICblood analyses and DUIC through self-reports was not statistically significant $\left(\boldsymbol{Z}_{\mathrm{diff}}=-0.05, \boldsymbol{p}=0.95\right)$ "

3. Figure 5 from the article is not correct, it is a duplicate of Figure 8. The original of Figure 5 was inserted in the final version of the manuscript sent to reviewers. Attached is the correct figure, with the changes made to point 1.

4. Additionally, some readers were unclear why were some articles removed from our analysis. We have specified the fact

\section{REFERENCES}

Asbridge, M., Mann, R., Cusimano, M. D., Trayling, C., Roerecke, M., Tallon, J. M., et al. (2014). Cannabis and traffic collision risk: findings from a case-crossover study of injured drivers presenting to emergency departments. Int. J. Public Health 59, 395-404. doi: 10.1007/s00038-013-0512-z

Gjerde, H., Normann, P. T., Christophersen, A. S., Samuelsen, S. O., and Mørland, J. (2011). Alcohol, psychoactive drugs and fatal road traffic accidents in Norway: a case-control study. Accid. Anal. Prev. 43, 1197-1203. doi: 10.1016/j.aap.2010.12.034

Gmel, G., Kuendig, H., Rehm, J., Schreyer, N., and Daeppen, J.-B. (2009). Alcohol and cannabis use as risk factors for injury-a case-crossover analysis in a Swiss hospital emergency department. BMC Public Health 9:40. doi: 10.1186/1471-2458-9-40

Hels, T., Lyckegaard, A., Simonsen, K. W., Steentoft, A., and Bernhoft, I. M. (2013). Risk of severe driver injury by driving with psychoactive substances. Accid. Anal. Prev. 59, 346-356. doi: 10.1016/j.aap.2013.06.003

Kuypers, K. P., Legrand, S. A., Ramaekers, J. G., and Verstraete, A. G. (2012). A case-control study estimating accident risk for alcohol, medicines and illegal drugs. PLOS ONE 7:e43496. doi: 10.1371/journal.pone.0043496

Laumon, B., Gadegbeku, B., Martin, J. L., Biecheler, M. B., and SAM Group (2005). Cannabis intoxication and fatal road crashes in France: population based case-control study. BMJ 331:1371. doi: 10.1136/bmj.38648.617986.1F

Li, G., Brady, J. E., and Chen, Q. (2013). Drug use and fatal motor vehicle crashes: a case-control study. Accid. Anal. Prev. 60, 205-210. doi: 10.1016/j.aap.2013.09.001 that two articles were removed due to multiple publication bias in the materials and methods section. However, to be clearer, we would like to add another sentence in the Results section/Search synthesis, namely: "If two articles contained overlapping data, the newest article was removed from the analysis."

5. In the Materials and Methods chapter, subchapter The Risk of Bias, line 4, instead of "and selection bias" should read "sampling bias."

The authors apologize for these mistakes. These errors does not change the scientific conclusions of the article in any way.

The original article has been updated.

Longo, M. C., Hunter, C. E., Lokan, R. J., White, J. M., and White, M. A. (2000). The prevalence of alcohol, cannabinoids, benzodiazepines and stimulants amongst injured drivers and their role in driver culpability: part ii: the relationship between drug prevalence and drug concentration, and driver culpability. Accid. Anal. Prev. 32, 623-632. doi: 10.1016/S0001-4575(99)00110-4

Movig, K. L., Mathijssen, M. P., Nagel, P. H., Van Egmond, T., De Gier, J. J., Leufkens, H. G., et al. (2004). Psychoactive substance use and the risk of motor vehicle accidents. Accid. Anal. Prev. 36, 631-636. doi: 10.1016/S0001-4575(03)00084-8

Mura, P., Chatelain, C., Dumestre, V., Gaulier, J. M., Ghysel, M. H., Lacroix, C., et al. (2006). Use of drugs of abuse in less than 30-yearold drivers killed in a road crash in France: a spectacular increase for cannabis, cocaine and amphetamines. Forensic Sci. Int. 160, 168-172. doi: 10.1016/j.forsciint.2005.09.006

Conflict of Interest Statement: The authors declare that the research was conducted in the absence of any commercial or financial relationships that could be construed as a potential conflict of interest.

Copyright (c) 2018 Hostiuc, Moldoveanu, Negoi and Drima. This is an open-access article distributed under the terms of the Creative Commons Attribution License (CC $B Y)$. The use, distribution or reproduction in other forums is permitted, provided the original author(s) and the copyright owner are credited and that the original publication in this journal is cited, in accordance with accepted academic practice. No use, distribution or reproduction is permitted which does not comply with these terms. 